\title{
Human iron transporters
}

\author{
Michael D. Garrick
}

Received: 20 April 2010/Accepted: 24 August 2010/Published online: 14 September 2010

(C) Springer-Verlag 2010

\begin{abstract}
Human iron transporters manage iron carefully because tissues need iron for critical functions, but too much iron increases the risk of reactive oxygen species. Iron acquisition occurs in the duodenum via divalent metal transporter (DMT1) and ferroportin. Iron trafficking depends largely on the transferrin cycle. Nevertheless, nondigestive tissues have a variety of other iron transporters that may render DMT1 modestly redundant, and DMT1 levels exceed those needed for the just-mentioned tasks. This review begins to consider why and also describes advances after 2008 that begin to address this challenge.
\end{abstract}

Keywords Divalent metal transporter (DMT1) .

Ferroportin - Isoforms - Transferrin - Ferric reductase . Iron-responsive element (IRE) · Iron regulatory protein (IRP)

Because the author recently had the opportunity to address a closely related topic [14], this review will largely be an update on that one with the emphasis on exploring issues that have arisen since then or were overlooked before or are specific for human iron transporters, again trying to encourage researchers to move to improve our understanding rather than to follow fashion. It will repeat information only where essential for understanding of a topic. New recent relevant reviews include coverage of iron acquisition and storage [8], impaired iron homeostasis in Parkinsonism [28], normal iron homeostasis from a molecular viewpoint [56], normal and pathological iron

M. D. Garrick ( $\bowtie)$

Department of Biochemistry, 140 Farber Hall, SUNY at Buffalo, 3435 Main St., Buffalo, NY 14214, USA

e-mail: mgarrick@buffalo.edu homeostasis in the eye [18], hereditary hemochromatosis [52], hepcidin's role as a regulator [36] and recycling of iron primarily by macrophage [2].

Human cells and tissues manage iron carefully. Nearly all of them need iron to supply redox functions in many pathways in both heme and non-heme proteins. Iron, however, helps to generate reactive oxygen species (ROS) via the same capability, thus the need for careful management.

Figure 1 depicts some iron fluxes that occur in humans. Essentially, all nutritional iron enters by absorption in the duodenum. Regulation of this absorption is critical because there is no known regulated process for removal of iron from the body. Newly absorbed iron moves through portal venous flow to the liver, where it is utilized for liver functions and stored by processes that at least normally buffer the supply of iron to other tissues. The largest flux is via circulation to the bone marrow, where erythropoiesis utilizes iron primarily to form hemoglobin that endures in circulating red blood cells for $\sim 120$ days. When red cells become effete, their iron is recovered in circulating and splenic macrophage and Kupffer cells of the liver. This recovery is normally very efficient, and most of the iron is reutilized in continuing erythropoiesis. The transporters that serve the fluxes just outlined are relatively well understood. One observation that captured the author's attention, however, relates to divalent metal transporter 1 (DMT1), the major iron importer; Beaumont's group [50] quantitated the relative amounts of DMT1mRNA (actually for two DMT1 isoforms, but transporter isoforms will be considered below) and found that the quantities in tissues other than the marrow and duodenum were often as high or higher than those in these two critical tissues. So, why is there so much iron transport capacity in other tissues? The observations are easily reproduced, so discounting them is 


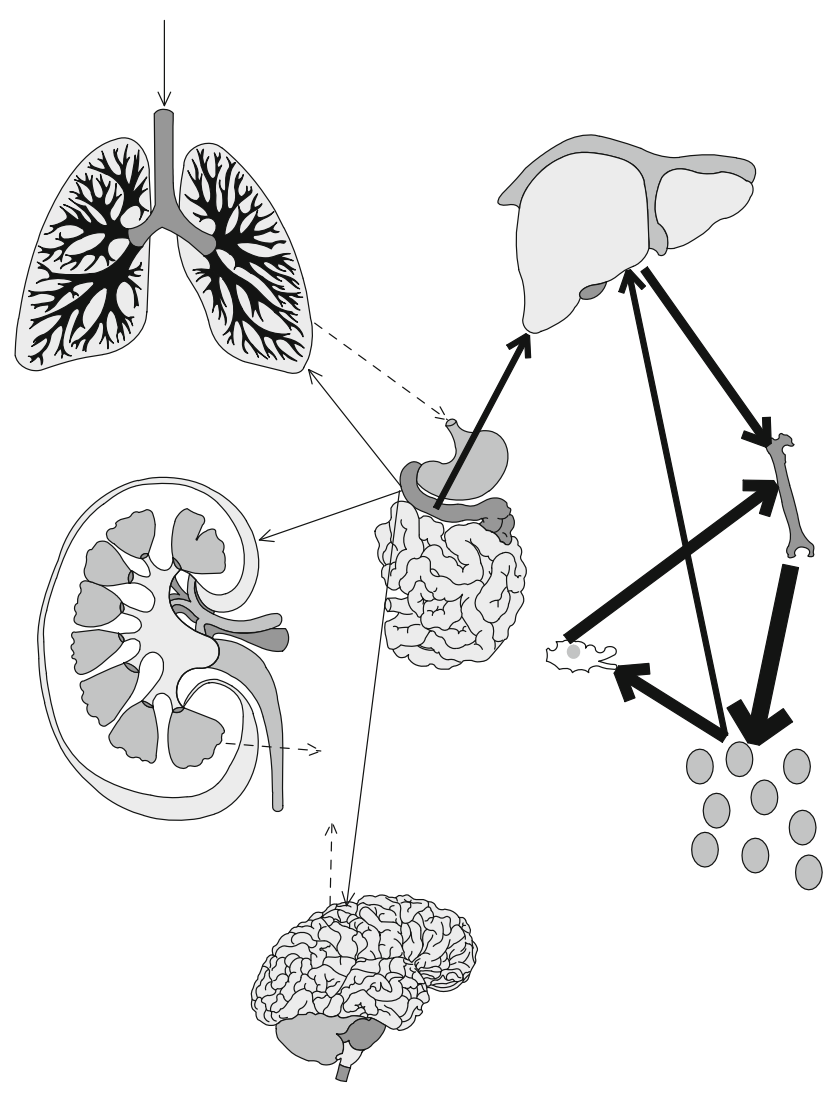

Fig. 1 Iron flux among specific tissues. The conventional scheme is in the center and to the right. Iron enters the body after absorption primarily in the duodenum (center) of the gastrointestinal (GI) tract. Portal veinous flow carries it to the liver (top right), where a portion will be stored if the supply exceeds immediate demands so the liver serves as a buffer. The main flux from the liver is to the bone marrow represented here by a femur (middle right) where incorporation in developing red blood cells (lower right) requires an even greater flux. Aged red cells are removed by macrophage (middle), many of which can reside in the spleen or marrow and Kupffer cells in the liver. These cells recycle the iron to the marrow for reutilization in erythropoiesis. It is also accepted that the circulation delivers iron to the lungs (upper left), kidneys (middle left), and brain (lower left) as well as to all other tissues but the flux into these tissues is lower. Is there reflux from these tissues? Certainly or probably would be the answers but the specifics represent frontiers in the study of iron homeostasis as do many of the specifics of the arrival of iron in these organs (see text). Also noted is that we certainly acquire some iron via the airways although that acquisition is not considered iron nutrition. Iron may move from the airways to the GI tract or from the kidneys back into circulation after filtration, and perhaps iron can be removed from the brain. In humans, the estimate for normal duodenal uptake flux is $1-2 \mathrm{mg} / \mathrm{day}$ of iron [21], balanced by unregulated excretion of the same magnitude; while $20-25 \mathrm{mg} /$ day enters erythrocytes balanced by a similar recovery from effete red cells. I have not found good estimates for other tissues but speculate that the other fluxes shown here are $<1 \mathrm{mg} /$ day. The relative sizes of the arrows represent these estimates and guesses. The macrophage is redrawn from Fig. 4 of an earlier review [14] with permission

not helpful. The left side of the figure begins to consider possible fluxes of iron relative to these organs. The airways will need iron nutritionally for their development, function, and survival. They will also have to contend with unneeded iron entering them in association with particulates such as desert and volcanic dust, when all we had to contend with was natural challenges and the detritus of human activities now that we have civilization. This iron may be absorbed and "regurgitated" by airways cells [16] to reach the GI tract via the mucociliary escalator. Iron also reaches the kidneys to supply local functions via circulation. There it clearly filters [51] and is re-adsorbed. The brain demands iron for many functions. Does iron ever recycle from this tissue? These are statements and questions where approaches are often absent or at early stages. Given that transfer into and recovery from erythrocytes occupies the majority of normal iron flux and much of the remainder involves duodenal acquisition, one can speculate that other tissues have a large "surge" capacity, and some of this review will be concerned with why.

\section{Duodenal iron acquisition}

Figure 2 depicts the passage of iron through a duodenal enterocyte. One can consider three stages in order: Uptake from the lumen of the GI tract; intracellular passage; and exit from the cell. We should remember, however, that the cell must also obtain iron from the circulation for its own needs when the nutritional supply is inadequate and that not all the iron that enters the cell from the lumen will exit on the mucosal side. DMT1 is the transporter responsible for $\mathrm{Fe}^{2+}$ entry but the iron has to be reduced by ascorbate through the action of Dcytb. The iron must be transcytosed to where it will exit the cell and enter the circulation. Transcytosis is definitely the stage about which the least is known. Although there is evidence that DMT1 moves with the iron [32], Núñez' group [37] recently reminded us that such data can also account for a loss of iron uptake after an iron challenge, traditionally called the mucosal block [54]. Earlier, there were similar observations in $\mathrm{Caco} 2$ cells supporting this interpretation [46]. Critical experiments are still needed to learn if these explanations for DMT1 movement are reliable. The findings that departure of DMT1 from the apical membrane correlates with decreased apical flux in Caco-2 cells and that antisense to DMT1 inhibits this flux [37] both support the mucosal block as an explanation, but participation of DMT1 in transcytosis is not excluded by such data. Iron exit from enterocytes depends on the transporter Fpn plus oxidation of $\mathrm{Fe}^{2+}$ to $\mathrm{Fe}^{3+}$ by $\mathrm{Hp}$ or $\mathrm{Cp}$ so that transferrin (Tf) can bind the exported $\mathrm{Fe}^{3+}$. We have already covered regulation of the export process [14] but call attention here to how repositioning of Fpn may help to accomplish this regulation even without turnover of the Fpn in the proteosome [37]. 
Iron absorption by enterocytes

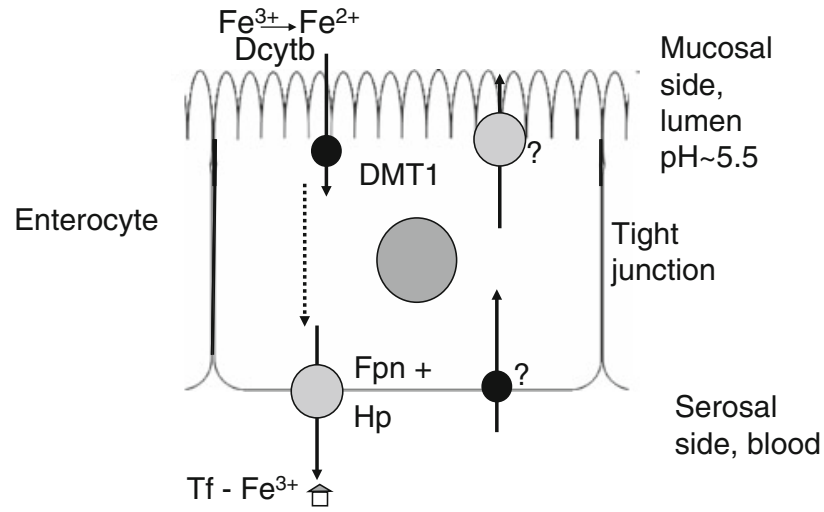

Fig. 2 Enterocyte iron absorption. The critical entry transporter on the apical surface of the enterocyte is DMT1. Given that DMT1 is specific for $\mathrm{Fe}^{2+}$ (as opposed to $\mathrm{Fe}^{3+}$ ), $\mathrm{Fe}^{3+}$ must be reduced prior to or concomitant with entry. The ferrireductase, duodenal cytochrome B (Dcytb), accomplishes this but does not appear to be an absolute requirement. Subsequently, iron must get to where it exits the cell, a process celled transcytosis (dashed arrow). The exit transporter, ferroportin (Fpn, but also called MTP1, Ireg1 or Slc40), probably acts on $\mathrm{Fe}^{2+}$ but reoxidation to $\mathrm{Fe}^{3+}$ by hephaestin $(\mathrm{Hp})$ or ceruloplasmin (Cp) as well as binding of the resultant $\mathrm{Fe}^{3+}$ to apo-transferrin (Tf) could occur in a relatively concerted fashion. The Tf receptor (TfR1) is probably also a part of the exit process although its role here, the reverse of the Tf cycle (below), is not yet well defined. Also yet to be well defined is the role of DMT1 (here shown with a ?) in possible basolateral uptake of iron noted in basolateral membrane vesicles [24] and recently supported [37]. Núñez et al. also propose that Fpn can allow iron to exit back into the lumen of the GI tract (also shown here with a ?). The figure is modified from Fig. 1 of the earlier review [14] with permission

Earlier, we [14] called attention to the lack of recent research on a speculative role of mucins interacting with DMT1 in the cellular acquisition of iron from the lumen of the duodenum. A few months later, coculture of cells that model enterocytes with the ones that model goblet (mucinsecreting) cells was described [27]. Such cocultures appear to predict iron bioavailability for foods [34] and look like a system where new insights can develop. Perhaps they can also encourage a new level of insight into how phytates, polyphenols, and other inhibitors render iron-rich plant foods like spinach into poor sources of iron.

\section{The Tf cycle: iron trafficking into erythroid cells as well as most other tissues}

Most cells acquire iron via the Tf cycle (Fig. 3). Physiologically, iron usually enters cells after binding to Tf; the $\mathrm{Fe}$-Tf or $\mathrm{Fe}_{2}$-Tf in turn binds to TfR1 on the cell surface. The Fe-Tf-TfR1 complex in turn enters the cell via endocytosis. Hence, we clearly must classify TfR1 semantically as a human iron transporter. Acidification of
The transferrin cycle

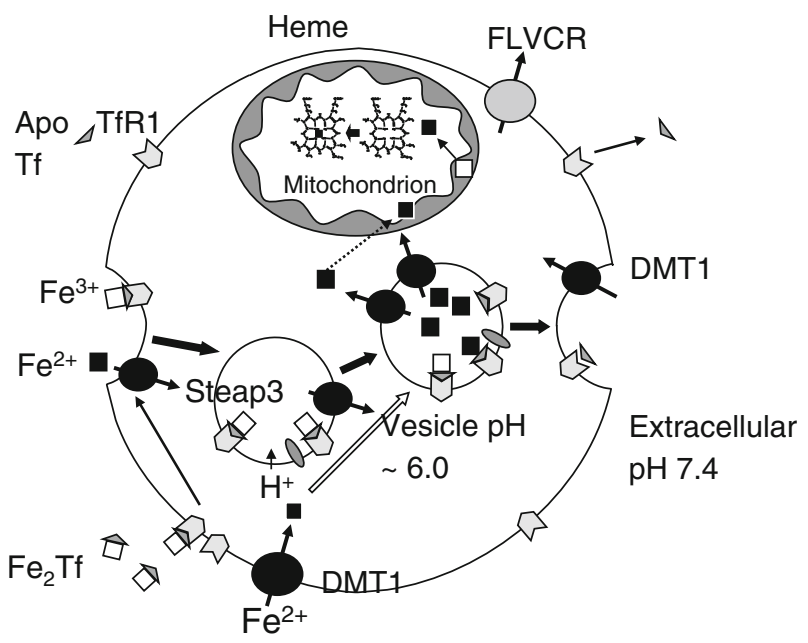

Fig. 3 The Tf cycle. The figure represents what happens in most cells but is specifically applicable to erythroid precursors. At the extracellular $\mathrm{pH}$ of 7.4, TfR1 on the cell surface binds Fe-Tf (with the Fe on either the $\mathrm{N}$ - or C-terminal lobe) or $\mathrm{Fe}_{2}$-Tf preferentially over apo-Tf. Endocytosis of the Fe-Tf-TfR1 complex occurs, and then the $\mathrm{pH}$ of that vesicle drops after the action of the vacuolar $\mathrm{H}^{+}$-ATPase. As it reaches $\sim 6.0$, the $\mathrm{Tf}-\mathrm{TfR} 1$ complex releases $\mathrm{Fe}^{3+}$ cooperatively. This release might be stimulated by reduction to $\mathrm{Fe}^{2+}$ by a ferrireductase, six-transmembrane epithelial antigen of the prostate (Steap3), represented here by a gray oval and by having a departing iron already reduced (see text). Apo-Tf-TfR1 exocytoses as a complex from the recycling endosome to the cell surface. The neutral $\mathrm{pH}$ at this location promotes the release of the apo-Tf from TfR1. The released $\mathrm{Fe}^{2+}$ is a substrate for DMT1 transport, exiting directly to the mitochondrion or indirectly after passage through the cytosol, perhaps as a constituent of the labile iron pool (LIP). DMT1 on the cell surface can probably directly import non-Tf-bound iron (NTBI). The figure is modified from [14] with permission

the endosome provokes dissociation of $\mathrm{Fe}^{3+}$ from the $\mathrm{Tf}-$ TfR1. Although we previously unintentionally implied [14] that this step makes $\mathrm{Fe}^{3+}$ available as a substrate for reduction by Steap3, it could be that Steap3 participates in the release of the iron as $\mathrm{Fe}^{2+}$ because the reduction potential of the iron is more within a range where intracellular reductants can drive the reaction when $\mathrm{Fe}^{3+}$ is associated with Tf-TfR1 [9]. Unless the sequence is as now suggested, there is a need to find a physiological reductant although proof that reduction occurs when the iron is still associated with Tf-TfR1 remains to be supplied.

In the previous review [14], we considered ferritin (ft) in a separate section, but the recent discovery that a form of $\mathrm{ft}$ can enter cells via the human TfR1 [30] places $\mathrm{ft}$ as an alternative substrate for the Tf cycle. Ft normally consists of 24 subunits of two types called $\mathrm{H}$ and $\mathrm{L}$ to distinguish the heavier chain from the lighter. The proportion of $\mathrm{H}$ and $\mathrm{L} \mathrm{ft}$ varies. $\mathrm{Li}$ et al. show that TfR1 is a receptor also for $\mathrm{H}$ $\mathrm{ft}$ but not for $\mathrm{L} \mathrm{ft}$ and that binding leads to $\mathrm{H} \mathrm{ft}$ entering endosomes and lysosomes. Potentially, $\mathrm{H} \mathrm{ft}$ can be a source 
of iron for cells and tissues via this route. The authors clearly distinguish this pathway from that for $\mathrm{H} \mathrm{ft}$ reliant on T-cell immunoglobulin-domain and mucin-domain protein 2 (TIM-2) in mice $[3,7,17]$. They state that murine TfR 1 does not bind human $\mathrm{H} f t$ nor murine $\mathrm{H} \mathrm{ft}$, suggesting that the mechanism for receptor recognition of $\mathrm{H} f t$ diverged between humans and mice. The properties imply that one should look for how well the pathway actually contributes to iron trafficking in human mutants with atransferrinemia or hypotransferrinemia, but that the similar mouse mutants will not be of value in such an appraisal.

\section{Macrophage and Nramp1}

Nramp1 (Natural resistance-associated macrophage protein 1) has its highest expression in macrophage as its name implies [14] and citations therein. There has now been an important advance that helps to define its functions and direction of transport [47]. The investigators showed that loss of either DMT1 or Nramp1 leads to a minor deficit in recycling hemoglobin after erythrophagocytosis. Simultaneous loss of both transporters, however, severely impairs iron recycling. Their work shows that Nramp1 plays a role in the phagosome similar to the one that DMT1 plays in the endosome: Exit of iron toward its destination of recovery for another round of hemoglobin formation. Their data also bear on the controversy on whether Nramp1 is a proton symporter like DMT1 or an antiporter because the function of Nramp1 is now demonstrably partially redundant to DMT1 [47], implying that Nramp1 is a proton symporter that provides a measure of resistance to many infections by depleting the phagosome of iron and perhaps manganese.

\section{Liver contributions}

Several aspects of iron transporter properties and regulation in the liver have been covered before [14] and in citations therein. There is value now in updating two aspects: efforts to modulate transporters and the role of the second Tf receptor (TfR2).

Weiss's group [31] have presented data showing that nifedipine, a calcium channel blocker, stimulates DMT1 transport activity. They also reported that nifedipine mobilizes iron from the liver of mice with primary and secondary iron overload and enhances urinary iron excretion. Another result was that nifedipine led to loss of serum iron in a fashion that related to DMT1 genotype in $+/+$ and $+/ m k$ mice where the $m k$ mutation is G185R in DMT1. These results offer nifedipine as a means of modulating iron overload in a fashion that would be off-label use of a USA FDA-approved drug. We [33] have not been able to reproduce the stimulation of DMT1 by nifedipine and suggest that the ability of photodegraded nifedipine to serve as an iron channel $[19,44,45]$ may account for some of their observations. Unfortunately, their statistical analysis [31] supporting the argument that the DMT1 mutation diminishes the loss of serum iron is flawed and the postulated role of DMT1 in supporting exit of iron would make DMT1 join Fpn as an iron exporter. We do have unpublished data (M. Garrick, L. Zhao, B. Hagerty, S. Gadersohi, A. Ghio, L. Garrick and B. Mackenzie 2009) that suggest that nifedipine treatment does decrease serum iron in rodents in a fashion that does not relate to the DMT1 genotype, so nifedipine could still be of interest for removing iron. Nifedipine's mechanism for doing so, however, and whether it does diminish liver iron both require more studies.

Although stimulation of DMT1 activity remains elusive, there are multiple reports of potential inhibitors. Ebselen, a seleno compound that may act via redox activity, clearly inhibits DMT1 [53]. Several polysulfonated dyes are also inhibitors [4].

Most published approaches to Fpn are based on its regulation by hepcidin and other regulators. In this context, the critical involvement of the liver in TfR2 (and HFE) modulation of hepcidin has just been confirmed [13] in mice. Another study [41] examines the role of two isoforms of TfR2 mRNA. The $\alpha$ isoform is longer and encodes a fulllength TfR2, while the $\beta$ isoform is shorter. By generating a mouse that lacks the $\alpha$ isoform but retains as a knock-in the $\beta$ isoform, this group suggests that its product is also involved in regulating Fpn transcription. Their results confirm the already identified function of the $\alpha$ isoform in hepcidin activation but also suggest that $\beta$ TfR 2 is more specifically involved in splenic Fpn function (iron efflux).

\section{Contributions from transporter isoforms}

Two human iron transporters have two or more isoforms with properties that insure that the isoforms act in different circumstances. These are DMT1 and Fpn.

The gene for human DMT1 produces 4 major transcripts (Fig. 4a). Although these are frequently referred to as alternative splicing, that terminology is incorrect and alternative transcripts should be used because the choice of promoter (for exon $1 \mathrm{~A}$ or exon $1 \mathrm{~B}$ ) and the choice of where to add poly A (terminating exon 16/16A or exon 17) determine the result rather than the choice of splice sites. Because the 16A portion of exon 16/16A contains an IRE, transcripts containing it are designated +IRE. Those which lack an IRE are frequently referred to as -IRE. IREs are relevant to the regulation of gene expression because tissues also contain iron regulatory proteins (IRPs) that can bind to IREs. IRP1 binds to IREs when the labile iron pool (LIP) is low but loses its IRE- 
Fig. 4 Iron transporter isoforms. a Alternate transcripts for DMT1. Exons are represented by blocks, introns by lines. Blocks are solid when the exons are found in mature mRNA but open when not (and instead untranscribed or part of an intron) except that 16A is stippled to emphasize when it is retained as part of an extended exon. Selection of one of the two promoters-1A [23] or 1B-leads to a choice of $5^{\prime}$ ends for DMT1 mRNA. Exons 2-15 are processed next (there is some alternate splicing for these but the physiological role is not yet defined). If polyadenylation occurs at the end of exon 16/16A, the entire exon remains in mature mRNA. The exon includes an ironresponsive element (IRE) that potentially can be bound by an iron regulatory protein (IRP). The mRNA will thus contain an IRE in the $3^{\prime}$ untranslated region (UTR). If polyadenylation occurs instead at the end of the next exon (17), splicing occurs from a small part of the preceding exon (16) and the IRE, and the remainder of 16A is part of the intron. This set of choices was first noted for rats [10], but soon also for humans [29]. Although the mRNA variants (1A, 1B, +IRE, -IRE) are frequently labeled alternative splicing, they actually represent alternate promoters and poly A sites. $\mathbf{b}$ The protein isoforms of DMT1. Human DMT1 has 543 internal amino acid residues common to all 4 forms here represented by black lines. Exon 1A contains an AUG codon, so it has 29 amino acid residues at the $\mathrm{N}$-terminus (here represented by a dark gray line) encoded by exons $1 \mathrm{~A}$ and 2. Exon 1B lacks an AUG, so the first amino acid residue (next AUG) is encoded within exon 2. Exon 17 encodes 25 unique amino acid residues, most conveniently designated -IRE and here represented by a light gray line. Exon $16 \mathrm{~A}$ encodes 18 unique amino acid residues, most conveniently designated +IRE and here represented by a gray line. c Alternate transcripts for Fpn. As in a, exons are represented by blocks, introns by lines. Blocks are solid when the exons are found in mature mRNA but open when not (and instead untranscribed or part of an intron) except that parts of 1a are stippled to suggest how frequently they are retained as part of the exon when the $1 \mathrm{~b}$ promoter initiates transcription. Selection of one of the two promoters - $1 \mathrm{a}$ or $\mathrm{b}$ [57] — leads to a choice of $5^{\prime}$ ends for Fpn mRNA. (It is unfortunate that the authors chose to designate $1 \mathrm{a}$ and $\mathrm{b}$ in a fashion inconsistent with the choices made years earlier for DMT1 but this is their nomenclature.) When the $1 \mathrm{~b}$ promoter is used, splicing proceeds from the $3^{\prime}$ donor sequence of exon $1 \mathrm{~b}$ to one of the 3 possible splice acceptors within what is wholly exon 1a if the 1a promoter was to be selected. All 3 acceptors are $3^{\prime}$ to the IRE so any of the 3 transcripts that start from exon $1 \mathrm{~b}$ exclude the IRE. This figure is based on data from Rouault's group [57], but not modified from their figures

binding properties to become a cytosolic aconitase when LIP levels are higher. IRP2 is relatively stable, as well as capable of IRE binding when LIP levels are low, but is degraded when LIP levels increase. Thus, both IRPs bind IREs in relative cellular iron deficiency and fail to bind in relative sufficiency. IREs in the $5^{\prime}$ UTR of mRNAs diminish the initiation of translation when occupied by an IRP. Because IRE(s) in the $3^{\prime}$ UTR can stabilize mRNA against degradation when occupied by an IRP, they potentially contribute to posttranscriptional regulation. We previously discussed [14] how challenging it is to distinguish regulation involving choice of promoter when the promoter is iron/hypoxia responsive from post-transcriptional IRE-based regulation.

The 4 isoforms of DMT1 mRNA (1A/+IRE, 1A/-IRE, 1B/+IRE, and 1B/-IRE) also encode related but distinct proteins (Fig. 4b). Potentially, differences between the
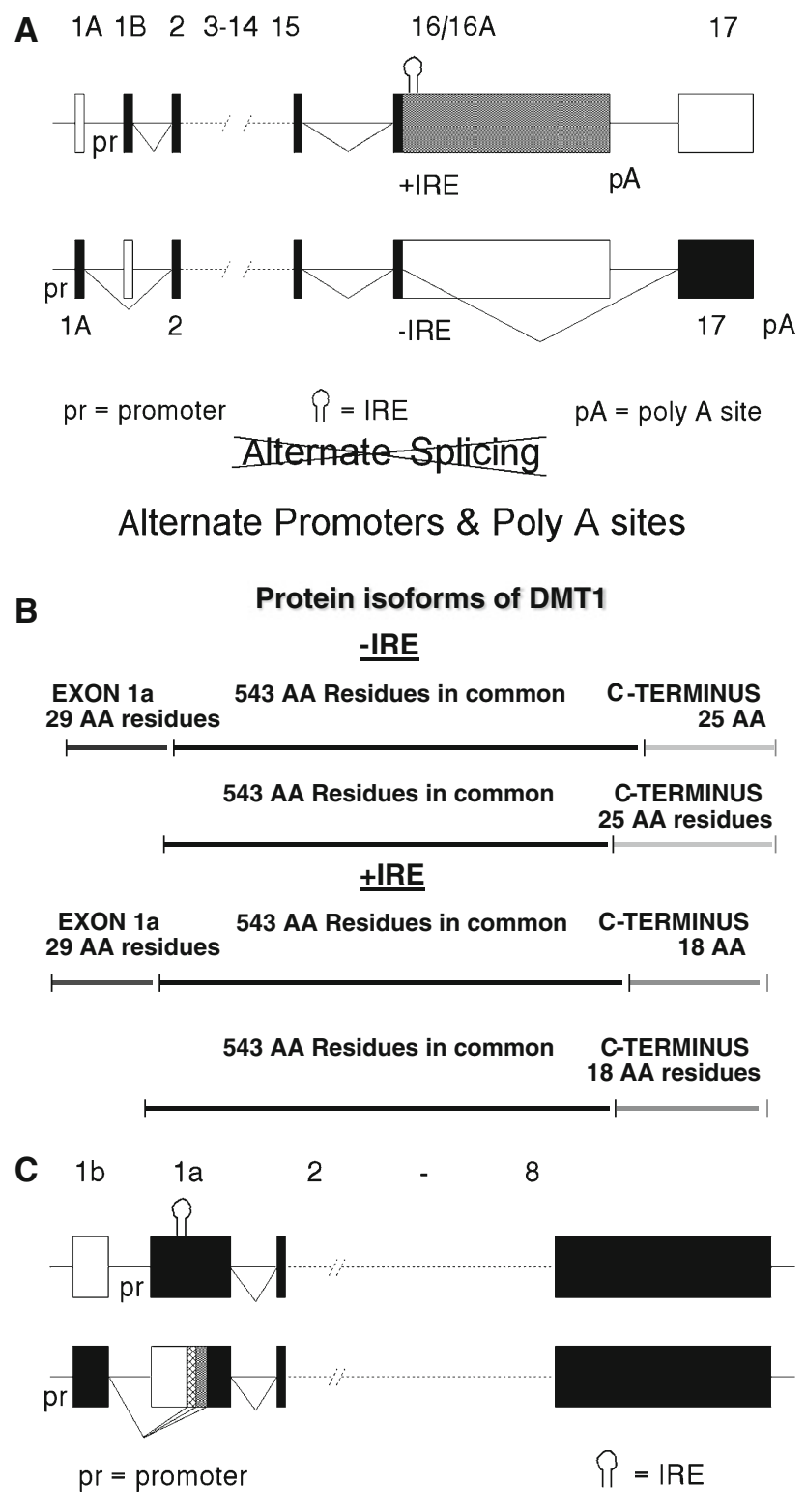

Alternate Promoters \& Alternate Splicing

$\mathrm{N}$-terminus that starts in exon $1 \mathrm{~A}$ and the one that starts in exon 2 and differences between the 18 C-terminal amino acid residues of the +IRE form and the 25 of the -IRE could affect localization of the transporter within the cell, thus where it functions and even where it turns over. Existing data do suggest the presence of such distinctions [5, 15, 24, 26, 38, 39, 48, 49].

Recently, Rouault's laboratory [57] described alternate transcripts for Fpn (Fig. 4c). It is the only known human iron export transporter, as such it regulates the exit of iron from enterocytes into circulation. Their findings resolve a paradox about the regulation of Fpn. Given that the only previously recognized mRNA isoform has an IRE in the $5^{\prime}$ UTR, IRPs binding to that IRE during iron deficiency would shut off 
synthesis of Fpn, preventing iron absorption when absorption is needed most. Zhang et al. have established that this paradox applies only to one isoform of Fpn mRNA where transcription initiates from its promoter upstream of exon 1a. For some other mRNA isoforms, transcription initiates farther upstream so that the first exon is $1 \mathrm{~b}$ where splicing to the middle or beyond of exon 1a leads to omission of the IRE. The transcripts that start with exon $1 \mathrm{~b}$ will then not be downregulated by iron deficiency. There is a choice of 3 possible splice acceptor sites for the 1a-b splicing, but it is unclear whether this choice has any effect on Fpn gene expression as all 3 lead to Fpn mRNA lacking an IRE. These same transcripts are also well expressed in erythroid differentiation, supporting the postulate [40] that iron homeostasis in these cells has privileged regulation to handle the heavy demand for iron. The Fpn amino acid sequence predicted by all of the mRNA isoforms is invariant, indicating that the targeting of their products is the same.

\section{Neural tissue and related cell types}

Because we previously reviewed this area [14] and there have been both an even more recently focused review [28] and another broader one that preceded [55], this section focuses on recent relevant data and a relationship that has been overlooked by many. Salazar et al. [43] have shown that the +IRE form of DMT1 is increased in the substantia nigra of Parkinson's disease patients. Given that both microcytic mice (gene symbol $m k$ ) and Belgrade rats (gene symbol $b$ ) have a G185R mutation that impairs DMT1 transport activity $[10,11]$, they could determine whether similar increases in DMT1 were part of an inflammatory etiology of neurodegeneration in two rodent models of Parkinson's disease or were part of a protective response. They used 1-methyl-4-phenyl-1, 2, 3, 6-tetrahydropyridine (MPTP) to induce Parkinsonism in mice. Homozygous $\mathrm{mk} / \mathrm{mk}$ mice retained more tyrosine hydroxylase-positive neurons from the substantia nigra than control $+/ m k$ or $+/+$ mice after MPTP intoxication. Stereotactical injection of 6-hydroxydopamine (6-OHDA) into the hippocampus leads to retrograde transport of the 6-OHDA and loss of neurons from the substantia nigra. Similarly, $b / b$ rats lost fewer tyrosine hydroxylase-positive neurons than control $+/ b$ or $+/+$ rats. Thus, DMT1 up-regulation in response to inflammation is likely to be part of a vicious cycle that contributes to neurodegeneration.

The increase in +IRE DMT1 in Parkinson's disease and these models for Parkinsonism can be accounted for in multiple ways: NF- $\kappa \mathrm{B}$ might be involved as it is frequently activated in inflammation, and the DMT1 1B promoter is responsive to this transcription factor [38, 39]. Another possibility is based on the observation that +IRE DMT1 increases. Possibly, IRP activation has occurred to stabilize +IRE DMT1 mRNA, although this response would be despite locally elevated iron levels. An interesting new connection relates to turnover of DMT1 protein. One of the studies of transcriptional regulation of DMT1 $[38,39]$ also showed that DMT1 isoforms are degraded primarily in the proteasome but also in the lysosome. Recently, we found that 1B DMT1 degradation depends on parkin [42]. Proteasomal degradation depends primarily on the ubiquitination pathway where 3 types of enzymes, E1-E3, are involved. E1 is responsible for ubiquitin activation; the E2 family is responsible for conjugation; while the E3 family ligates ubiquitin to the protein target (here DMT1). Parkin is an E3 ligase; mutants in the PARK-2 gene account for the majority of autosomal recessive juvenile Parkinson's disease. Our data show that 1A DMT1 is not affected by transient expression of parkin, while +IRE and -IRE 1B DMT1 are degraded. By immuno-depleting 1A DMT1, we verified that the $1 \mathrm{~B}$ (or 2) forms are degraded by wild type but not by mutant parkin [42]. Although most of our experiments were in neuronal models, lymphocytes from humans who have a PARK-2 mutation revealed that $1 \mathrm{~B}$ DMT1 levels increased, so parkin affects DMT1 levels in non-neuronal tissue too [42].

Parkin is not the only E3 ubiquitin ligase that regulates DMT1 turnover; the Nedd4 family member WWP2 also diminishes DMT1 levels [12]. Although members of the Nedd4 family ordinarily interact with substrates via their so-called WW domains, DMT1 does not have any WW domains. Instead, DMT1 interacts with 2 WW domaininteracting proteins called Nedd4 family-interacting proteins 1 and 2 (Ndfip1 and Ndfip2), which are considered to have roles in protein trafficking. Interestingly, Ndfip1 knockout mice have increased DMT1 plus notable hepatic iron deposition, making Ndfip1 relevant to iron homeostasis. Using human neurons, Howitt and collaborators [22] found that the Ndfip1 is up-regulated and binds to DMT1 in response to $\mathrm{Fe}$ and cobalt (Co) exposure. Apparently, this response mediates the degradation of DMT1 to decrease metal entry. Ndfip1 over-expression protects neurons from metal toxicity; and decreasing Ndfip1 by RNAi leads to hypersensitivity to metals. Brains from Ndfip1 knockout mice exposed to $\mathrm{Fe}$ accumulate excess $\mathrm{Fe}$ within neurons. These data suggest that iron transporters and their regulation are very critically involved in neurodegeneration.

There is another iron transporter connection to neuronal properties that provokes re-examination of some older metabolic data [6]. Carlson et al. created mice with hippocampal ablation of DMT1; local iron deficiency accompanied the loss of DMT1. Spatial memory training induced the increased hippocampal DMT1 expression in normal mice, but those with a hippocampal DMT1 knockout performed less well on spatial memory tasks. 
Hippocampal neurons are richly populated with $\mathrm{N}$-methyl d-aspartate (NMDA) receptors that may well participate in the learning process. Another group [20] has shown that brief exposure of primary hippocampal cultures to $50 \mu \mathrm{M}$ NMDA induces $24 \mathrm{~h}$ later increased expression of $1 \mathrm{~B}$ and +IRE DMT1 mRNA, but not of DMT1-IRE mRNA. Both actinomycin D and the NMDA receptor antagonist, MK801, block the induction. 1B and +IRE DMT1 mRNA also went up in the hippocampus of rats after spatial memory training. The mice with hippocampal ablation of DMT1 had weakened energy metabolism and diminished glutamatergic neurotransmission [6]. While the basis for weakened energy metabolism is likely to be the connection between local iron deficiency and mitochondrial dysfunction as reviewed previously [14], there is a surprising but ultimately reasonable linkage between iron transport and glutamate signaling [35]. McGahan et al. start from the recognition that IRP1 when iron replete is cytosolic aconitase, thus one can conclude that this enzyme is regulated by iron status. It catalyzes the reaction citrate $\rightarrow$ isocitrate. Cytoplasmic isocitrate dehydrogenase can then convert isocitrate $\rightarrow \alpha$-ketoglutarate while generating a reducing equivalent as NADPH. The reaction $\alpha$-ketoglutarate $\rightarrow$ glutamate where glutamate dehydrogenase reductively aminates the substrate is a source of glutamate. The authors demonstrate that retinal-pigmented epithelial cells and cultured neuronal cells generate glutamate in an iron-dependent fashion. They point out that dysregulation of iron homeostasis and glutamate metabolism frequently occur together in neurodegenerative conditions. Although the excitatory toxicity of the glutamatergic response and the ROS contributions of excess iron usually attract attention from very different groups of researchers, this work points out that they should be considered together, even coordinately.

The same group [25] also uncovered a relationship where the level of iron transported into retinal-pigmented epithelial cells, neurons, or cultured lens epithelial cells would affect the cells' ability to manage ROS. Glutamate is also a precursor of the cellular reductant glutathione (GSH) and critically involved in making cysteine available for GSH synthesis via a glutamate/cystine antiporter. In this study, the authors showed that iron regulates L-cystine uptake and the downstream production of GSH. Thus, at least under normal circumstances, increased iron importation could lead to improved management of ROS. This series of results and many other issues in iron homeostasis for the eye have been recently reviewed by the same group [18].

\section{Perspectives}

I have generated a list (Table 1) of potential transporters to provide the reader with a summary of the transporters currently worthy of consideration. It is very exciting to see advances made in iron transporters in just 1 year since the last review [14]. There is now a demonstration that the microRNA Let-7d down-regulates -IRE DMT1 mRNA as erythroid cells differentiate [1]. Nevertheless, the areas

Table 1 Potential and actual human iron transporters

\begin{tabular}{|c|c|c|}
\hline Abbreviation & Name(s) & What it does or might do \\
\hline DMT1 & Divalent metal (ion) transporter & \multirow{4}{*}{$\begin{array}{l}\text { It is the major duodenal importer of ferrous iron and } \\
\text { other metal ions; it is also responsible for exit of } \\
\text { ferrous iron from endosomes during the Tf cycle; } \\
\text { this transporter also participates in Tf-independen } \\
\text { iron entry into cells (non-Tf-bound iron uptake) } \\
\text { and possibly in transcytosis of iron across } \\
\text { enterocytes }\end{array}$} \\
\hline DCT1 & Divalent cation transporter & \\
\hline Nramp2 & $\begin{array}{l}\text { Natural resistance-associated } \\
\text { macrophage protein } 2\end{array}$ & \\
\hline Slc11a2 & Solute carrier $11 \mathrm{a} 2$ & \\
\hline Fpn & Ferroportin & \multirow{4}{*}{$\begin{array}{l}\text { It is the only known cellular iron exporter in } \\
\text { mammals; this distinction is physiologically } \\
\text { important even if the ability of DMT1 to support } \\
\text { endosomal iron exit makes it also a semantic poin }\end{array}$} \\
\hline MTP1 & Metal transporter protein & \\
\hline Ireg1 & Iron-regulated transporter & \\
\hline Slc40 & Solute carrier 40 & \\
\hline Nramp1 & $\begin{array}{l}\text { Natural resistance-associated } \\
\text { macrophage protein } 1\end{array}$ & $\begin{array}{l}\text { Identified initially by the phenotype of resistance to } \\
\text { many microbial infections, this transporter } \\
\text { probably participates in the exit of iron and } \\
\text { manganese from phagosomes }\end{array}$ \\
\hline Tf & Transferrin & $\begin{array}{l}\text { It carries ferric iron in the plasma, lymph, and } \\
\text { cerebrospinal fluid behaving as an iron transporter } \\
\text { in conjunction with TfR } 1\end{array}$ \\
\hline
\end{tabular}


Table 1 continued

\begin{tabular}{|c|c|c|}
\hline Abbreviation & Name(s) & What it does or might do \\
\hline TfR1 & Tf receptor 1 & $\begin{array}{l}\text { It binds } \mathrm{Tf} \text { to deliver iron into cells with the } \\
\text { transport process due to receptor-mediated } \\
\text { endocytosis }\end{array}$ \\
\hline TfR2 & Tf receptor 2 & $\begin{array}{l}\text { It may also deliver Tf-bound iron and even iron not } \\
\text { bound to Tf to some cells }\end{array}$ \\
\hline $\mathrm{Ft}$ & Ferritin & $\begin{array}{l}\text { It is primarily an iron storage protein, but } \mathrm{H} \text { ft may } \\
\text { also participate in iron transport by binding to } \\
\text { TfR1 }\end{array}$ \\
\hline Zip14 & Zrt- and Irt-like & Although it was initially identified as a $\mathrm{Zn}$ \\
\hline Slc39a14 & Protein 14 & $\begin{array}{l}\text { transporter, Zip } 14 \text { is responsible for at least a part } \\
\text { of iron not bound to Tf uptake in the liver. More } \\
\text { speculatively, Zip8 may also be an iron transporter }\end{array}$ \\
\hline Ngal 24p3 lipocalin(-2) uterocalin & $\begin{array}{l}\text { Neutrophil gelatinase-associated } \\
\text { lipocalin }\end{array}$ & $\begin{array}{l}\text { This protein binds iron bound to an internal } \\
\text { siderophore that is yet to be identified. It and its } \\
\text { receptor are involved in iron withholding during } \\
\text { infection and early kidney development }\end{array}$ \\
\hline None & Ca channels & $\begin{array}{l}\text { Some Ca channels may also be routes for iron } \\
\text { uptake. In addition, there is evidence that the } \\
\text { G185R mutation of DMT1 leads to enhanced } \\
\text { behavior as a Ca channel for DMT1 }\end{array}$ \\
\hline TRPML1 & $\begin{array}{l}\text { Transient receptor potential } \\
\text { mucolipidosis-associated protein }\end{array}$ & \multirow{2}{*}{$\begin{array}{l}\text { Recently shown to act as a channel for iron exit from } \\
\text { endosomes and lysosomes, it is best known as a } \\
\text { protein in which mutations can cause } \\
\text { mucolipidosis type IV disease }\end{array}$} \\
\hline MCOLN1 & Mucolipin 1 & \\
\hline None & Mobilferrin & $\begin{array}{l}\text { It was postulated to be a form of calreticulin but also } \\
\text { a major iron transporter, but whether it is or not is } \\
\text { not known }\end{array}$ \\
\hline
\end{tabular}

Because the author is unaware of advances for some of the transporters, not all of them appear in the text even when cited here for complete coverage. For references for those not covered in the text, consult our last review [14]

identified for future studies (some of which were past areas that had fallen out of favor) have seen little by the way of new results. I would like to believe that this is not my failure as a prophet but rather that there has not yet been enough time for a too cautious attitude among funding sources "to obtain new knowledge that is likely to move forward our management of degenerative diseases and aging".

Acknowledgments I thank Dr. AL Crumbliss for drawing to my attention that it might be more felicitous to what actually happens to consider that Steap3 reduction could occur before release of iron from transferrin. Dr. Laura Garrick carefully read and critiqued multiple versions of this review.

\section{References}

1. Andolfo I, De Falco L et al (2010) Regulation of divalent metal transporter 1 (DMT1) non-IRE isoform by the microRNA Let7d in erythroid cells. Haematologica 95(8):1244-1252

2. Beaumont C, Delaby C (2009) Recycling iron in normal and pathological states. Semin Hematol 46(4):328-338
3. Boddaert N, Le Quan Sang KH et al (2007) Selective iron chelation in Friedreich ataxia: biologic and clinical implications. Blood 110(1):401-408

4. Buckett PD, Wessling-Resnick M (2009) Small molecule inhibitors of divalent metal transporter-1. Am J Physiol Gastrointest Liver Physiol 296(4):G798-G804

5. Canonne-Hergaux F, Gruenheid S et al (1999) Cellular and subcellular localization of the Nramp2 iron transporter in the intestinal brush border and regulation by dietary iron. Blood 93(12):4406-4417

6. Carlson ES, Tkac I et al (2009) Iron is essential for neuron development and memory function in mouse hippocampus. J Nutr 139(4):672-679

7. Chen TT, Li L et al (2005) TIM-2 is expressed on B cells and in liver and kidney and is a receptor for $\mathrm{H}$-ferritin endocytosis. J Exp Med 202(7):955-965

8. De Domenico I, McVey Ward D et al (2008) Regulation of iron acquisition and storage: consequences for iron-linked disorders. Nat Rev Mol Cell Biol 9(1):72-81

9. Dhungana S, Taboy $\mathrm{CH}$ et al (2004) Redox properties of human transferrin bound to its receptor. Biochemistry 43(1): 205-209

10. Fleming MD, Romano MA et al (1998) Nramp2 is mutated in the anemic Belgrade (b) rat: evidence of a role for Nramp2 in endosomal iron transport. Proc Natl Acad Sci USA 95(3):1148-1153 
11. Fleming MD, Trenor CI et al (1997) Microcytic anaemia mice have a mutation in Nramp2, a candidate iron transporter gene. Nature Genet 16(4):383-386

12. Foot NJ, Dalton HE et al (2008) Regulation of the divalent metal ion transporter DMT1 and iron homeostasis by a ubiquitindependent mechanism involving Ndfips and WWP2. Blood 112(10):4268-4275

13. Gao J, Chen J et al (2010) Hepatocyte-targeted HFE and TFR2 control hepcidin expression in mice. Blood 115(16):3374-3381

14. Garrick MD, Garrick LM (2009) Cellular iron transport. Biochim Biophys Acta Gen Subj 1790(5):309-325

15. Garrick MD, Kuo H-C et al (2006) Comparison of mammalian cell lines expressing distinct isoforms of divalent metal transporter 1 in a tetracycline-regulated fashion. Biochem $\mathbf{J}$ 398(3):539-546

16. Ghio AJ, Turi $\mathrm{J}$ et al (2006) Iron homeostasis in the lung. Biol Res 39(a):67-77

17. Ghio AJ, Turi JL et al (2007) Lung injury after ozone exposure is iron dependent. Am J Physiol Lung Cell Mol Physiol 292(1): L134-L143

18. Goralska M, Ferrell $\mathrm{J}$ et al (2009) Iron metabolism in the eye: a review. Exp Eye Res 88(2):204-215

19. Gruen AB, Zhou J et al (2001) Photodegraded nifedipine stimulates uptake and retention of iron in human epidermal keratinocytes. J Investig Dermatol 116(5):774-777

20. Haeger P, Álvarez Á et al (2010) Increased hippocampal expression of the divalent metal transporter 1 (DMT1) mRNA variants $1 \mathrm{~B}$ and +IRE and DMT1 protein after NMDA-receptor stimulation or spatial memory training. Neurotox Res 17(3):238-247

21. Hentze MW, Muckenthaler MU et al (2004) Balancing acts: molecular control of mammalian iron metabolism. Cell 117(3):285-297

22. Howitt J, Putz U et al (2009) Divalent metal transporter 1 (DMT1) regulation by Ndfip1 prevents metal toxicity in human neurons. Proc Natl Acad Sci 106(36):15489-15494

23. Hubert N, Hentze MW (2002) Previously uncharacterized isoforms of divalent metal transporter (DMT)-1: implications for regulation and cellular function. Proc Natl Acad Sci USA 99(19):12345-12350

24. Knöpfel M, Zhao L et al (2005) Transport of divalent transitionmetal ions is lost in small-intestinal tissue of $b / b$ Belgrade rats. Biochemistry 44(9):3454-3465

25. Lall MM, Ferrell J et al (2008) Iron regulates L-cystine uptake and glutathione levels in lens epithelial and retinal pigment epithelial cells by its effect on cytosolic aconitase. Invest Ophthalmol Vis Sci 49(1):310-319

26. Lam-Yuk-Sung S, Touret $\mathrm{N}$ et al (2005) Carboxy-terminus determinants of the iron transporter DMT1/SLC11A2 isoform II $(-\mathrm{IRE} / 1 \mathrm{~B})$ mediate internalization from the plasma membrane into recycling endosomes. Biochemistry 44:12149-12159

27. Laparra J, Glahn R et al (2009) Different responses of Fe transporters in Caco-2/HT29-MTX cocultures than in independent Caco-2 cell cultures. Cell Biol Int 33(9):971-977

28. Lee DW, Andersen JK (2010) Iron elevations in the aging parkinsonian brain: a consequence of impaired iron homeostasis? J Neurochem 112(2):332-339

29. Lee PL, Gelbart T et al (1998) The human Nramp2 gene: characterization of the gene structure, alternative splicing, promoter region and polymorphisms. Blood Cells Mol Dis 24(9):199-215

30. Li L, Fang CJ et al (2010) Binding and uptake of H-ferritin are mediated by human transferrin receptor-1. Proc Natl Acad Sci 107(8):3505-3510

31. Ludwiczek S, Theurl I et al (2007) $\mathrm{Ca}^{2+}$ channel blockers reverse iron overload by a new mechanism via divalent metal transporter1. Nat Med 13(4):448-454
32. Ma Y, Yeh M et al (2006) Iron imports. V. Transport of iron through the intestinal epithelium. Am J Physiol Gastrointest Liver Physiol 290:G417-G422

33. Mackenzie B, Shawki A et al (2010) Calcium-channel blockers do not affect iron transport mediated by divalent metal-ion transporter-1. Blood 115(20):4148-4149

34. Mahler GJ, Shuler ML et al (2009) Characterization of Caco-2 and HT29-MTX cocultures in an in vitro digestion/cell culture model used to predict iron bioavailability. J Nutr Biochem 20(7):494-502

35. McGahan MC, Harned $\mathbf{J}$ et al (2005) Iron alters glutamate secretion by regulating cytosolic aconitase activity. Am J Physiol Cell Physiol 288(5):C1117-C1124

36. Nemeth E, Ganz T (2009) The role of hepcidin in iron metabolism. Acta Haematol 122(2-3):78-86

37. Núñez MT, Tapia V et al (2010) Iron supply determines apical/ basolateral membrane distribution of intestinal iron transporters DMT1 and ferroportin 1. Am J Physiol Cell Physiol 298(3): C477-C485

38. Paradkar PN, Roth JA (2006) Nitric oxide transcriptionally downregulates specific isoforms of divalent metal transporter (DMT1) via NF-kappaB. J Neurochem 96(6):1768-1777

39. Paradkar PN, Roth JA (2006) Post-translational and transcriptional regulation of DMT1 during P19 embryonic carcinoma cell differentiation by retinoic acid. Biochem J 394(1):173-183

40. Ponka P (1997) Tissue-specific regulation of iron metabolism and heme synthesis: distinct control mechanisms in erythroid cells. Blood 89(1):1-25

41. Roetto A, Di Cunto F et al (2010) Comparison of three Tfr2-deficient murine models suggests distinct functions for TFR2 alpha and beta isoforms in different tissues. Blood 115(16):3382-3389

42. Roth JA, Singleton S et al (2010) Parkin regulates metal transport via proteasomal degradation of the $1 \mathrm{~B}$ isoforms of divalent metal transporter 1. J Neurochem 113(2):454-464

43. Salazar J, Mena N et al (2008) Divalent metal transporter 1 (DMT1) contributes to neurodegeneration in animal models of parkinson's disease. Proc Natl Acad Sci 105(47):18578-18583

44. Savigni DL, Morgan EH (1996) Mediation of iron uptake and release in erythroid cells by photodegradation products of nifedipine. Biochem Pharmacol 51(12):1701-1709

45. Savigni DL, Wege D et al (2003) Iron and transition metal transport into erythrocytes mediated by nifedipine degradation products and related compounds. Biochem Pharmacol 65(8):1215-1226

46. Sharp P, Tandy S et al (2002) Rapid regulation of divalent metal transporter (DMT1) protein but not mRNA expression by nonhaem iron in human intestinal Caco-2 cells. FEBS Lett 510(1-2):71-76

47. Soe-Lin S, Apte SS et al (2010) Both Nramp1 and DMT1 are necessary for efficient macrophage iron recycling. Exp Hematol 38(8):609-617

48. Tabuchi M, Tanaka $\mathrm{N}$ et al (2002) Alternative splicing regulates the subcellular localization of divalent metal transporter 1 isoforms. Mol Biol Cell 13:4371-4387

49. Tabuchi M, Yanatori I et al (2010) Retromer-mediated direct sorting is required for proper endosomal recycling of the mammalian iron transporter DMT1. J Cell Sci 123(5):756-766

50. Tchernitchko D, Bourgeois $M$ et al (2002) Expression of the two mRNA isoforms of the iron transporter Nramp2/DMTI in mice and function of the iron responsive element. Biochem $\mathrm{J}$ 363(3):449-455

51. Wareing M, Ferguson CJ et al (2000) In vivo characterization of renal iron transport in the anaesthetized rat. J. Physiol (Lond.) 524(2): 581-586 
52. Weiss G (2010) Genetic mechanisms and modifying factors in hereditary hemochromatosis. Nat Rev Gastroenterol Hepatol 7(1):50-58

53. Wetli HA, Buckett PD et al (2006) Small-molecule screening identifies the selanazal drug ebselen as a potent inhibitor of DMT1-mediated iron uptake. Chem Biol 13(9):965-972

54. Wheby MS, Jones LG et al (1964) Studies on iron absorption. Intestinal regulatory mechanisms. J Clin Invest 43(7):1433-1442
55. Zecca L, Youdim M et al (2004) Iron, brain ageing and neurodegenerative disorders. Nat Rev Neurosci 5(11):863-873

56. Zhang A, Enns C (2009) Molecular mechanisms of normal iron homeostasis. Hematol Am Soc Hematol Educ Progr 2009:207-214

57. Zhang D-L, Hughes RM et al (2009) A ferroportin transcript that lacks an iron-responsive element enables duodenal and erythroid precursor cells to evade translational repression. Cell Metab 9(5):461-473 